\title{
Análise comparativa entre torneira convencional e torneira de funcionamento hidromecânico instaladas em um campus universitário
}

\author{
Comparative analysis between ordinary and self-closing \\ taps installed in a university campus
}

\begin{abstract}
Roberta J acoby Cureau
Andreza Kalbusch

Elisa Henning

Resumo

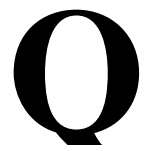

uando se trata de uso racional da água, a substituição de equipamentos hidrossanitários convencionais por economizadores de água é uma prática comum nas edificações de uso público. Neste artigo é apresentada uma comparação entre duas torneiras de lavatório, uma convencional com registro de pressão e outra de funcionamento hidromecânico, instaladas em um campus universitário. Foram comparados consumo de água, número de acionamentos e consumo por acionamento das torneiras utilizando técnicas estatísticas descritivas e inferenciais. Os dados foram coletados a partir de sensores de fluxo instalados nas ligações flexíveis das torneiras. As médias dos dados diários de consumo de água e de volume por acionamento da torneira convencional foram cerca de três vezes maiores do que as médias diárias da torneira de funcionamento hidromecânico. A aplicação do teste de Mann-Whitney permitiu inferir que não havia preferência dos usuários por utilizar um dos modelos de torneira. Durante a coleta de dados, a torneira convencional apresentou indícios de desperdícios decorrentes do mau fechamento da sua válvula e do uso excessivo de água pelos usuários. Assim, constatou-se que, neste estudo, a torneira de funcionamento hidromecânico apresentou menor consumo de água, além de evitar perdas em função do mau uso do equipamento.

Palavras-chave: Equipamentos economizadores de água. Torneira de funcionamento hidromecânico. Uso racional da água.

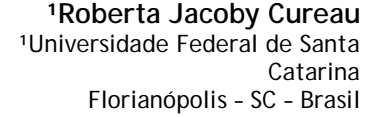

${ }^{2}$ Andreza Kalbusch ${ }^{2}$ Universidade do Estado de Santa Catarina J oinville - SC - Brasil

${ }^{3}$ Elisa Henning ${ }^{3}$ Universidade do Estado de Santa J oinville - SC - Brasil

Recebido em 06/06/18 Aceito em 07/08/18

\section{Abstract}

The replacement of ordinary plumbing fixtures by water-saving ones is a common practice in public buildings. This paper presents a comparison between two lavatory taps, an ordinary one and a self-closing one, installed at a university campus. Water consumption, number of uses per day and water consumption per activation were compared using statistical methods (exploratory data analysis and statistical tests). Data were obtained by installing water flow sensors in each tap. The average daily volume consumed and the average volume per activation for the ordinary tap were three times higher than the results found for the self-closing one. By applying the Mann-Whitney test, it was concluded that users did not show any preferences for either tap. During data collection, the ordinary tap presented some evidence of water waste because this plumbing fixture was sometimes left open and due to excessive use of water by users. Hence, the conclusion of this study is that water consumption was lower in the self-closing tap, which also prevented water waste caused by the incorrect use of ordinary taps.

Keywords: Self-closing tap. Water conservation. Water-saving plumbing fixtures.
\end{abstract}




\section{Introdução}

A redução da disponibilidade superficial de água e o contínuo crescimento da população e consequente aumento da demanda por água potável intensificaram a preocupação com a manutenção das fontes desse recurso e com o seu manejo sustentável (MUTHUKUMARAN; BASKARAN; SEXTON, 2011). As autoridades têm o desafio de assegurar o fornecimento de água para atender a demanda em face de problemas como a seca, o aumento da população e as mudanças climáticas (JORGENSEN; GRAYMORE; O’TOOLE, 2009). Neste sentido, a gestão do uso da água é imprescindível e a redução do seu consumo no ambiente urbano poderia reduzir a pressão sobre os sistemas hídricos locais (MOSTAFAVI; GÁNDARA; HOQUE, 2018).

As estratégias para conservação da água nas edificações podem incluir mudanças de comportamento (que podem ocorrer a partir de campanhas educativas e políticas tarifárias, por exemplo) e mudanças nos sistemas hidrossanitários, como instalação de equipamentos economizadores e uso de fontes alternativas de água (MEIRELES et al., 2017).

A substituição de equipamentos hidrossanitários convencionais por modelos economizadores de água é uma medida que proporciona economia significativa de água nas edificações (KELLY, 2015). Contudo, o consumo de água não depende apenas das características dos aparelhos, mas também de fatores relacionados ao meio (ROMANO; SALVATI; GUERRINI, 2016) е aо comportamento dos usuários (JORGENSEN; GRAYMORE; O’TOOLE, 2009). Desta forma, mesmo que a economia de água decorrente da instalação de equipamentos hidrossanitários tenha menor dependência da ação dos usuários (MARINOSKI; ANDRADE, 2010), as mudanças nos sistemas hidrossanitários algumas vezes influenciam suas preferências, e isso pode modificar os benefícios previstos quando do planejamento das estratégias para redução do consumo de água (MEIRELES et al., 2017).

O aumento da utilização de equipamentos economizadores de água e a variedade de modelos presentes no mercado nacional tornam necessária a realização de estudos para avaliar os impactos e os benefícios do uso desses aparelhos em comparação aos convencionais, bem como uma possível preferência dos usuários por utilizar esses modelos de equipamentos. Portanto, o objetivo desse artigo é comparar o consumo de água de duas torneiras de lavatório, sendo uma convencional com registro de pressão e outra com funcionamento hidromecânico, instaladas no banheiro de um campus universitário.
A comparação dos dois equipamentos foi feita a partir de métodos estatísticos (análise exploratória de dados e testes estatísticos). Foi avaliado também se há uma predileção dos usuários por utilizar um dos modelos de torneira.

\section{Revisão bibliográfica}

As torneiras de lavatório representam percentuais de consumo significativos em estudos desenvolvidos em diferentes tipologias de edifícios: $17 \%$ em residências unifamiliares (WILLIS et al., 2013); entre $10,5 \%$ e $23,4 \%$ em edifícios residenciais multifamiliares (GHISI; FERREIRA, 2007); de 6,6\% a 31,2\% em edificações públicas (KAMMERS; GHISI, 2006); e entre 6,8\% e 38,4\% em edifícios comerciais (PROENÇA; GHISI, 2010). Em ambientes universitários, Alexandre, Kalbusch e Henning (2017) verificaram que o indicador de consumo em um bloco de salas de aula era 2,901 litros/aluno/dia, sendo que as torneiras de lavatório correspondiam a 0,553 litros/aluno/dia (19\%). Assim, a adoção de tecnologias economizadoras de água nesses equipamentos pode promover redução do consumo nas edificações (MILLOCK; NAUGES, 2010).

Segundo Marinoski e Andrade (2010), para o setor residencial sugere-se a instalação de arejadores na saída das torneiras. Esses dispositivos incorporam ar ao fluxo de água e isso modifica a vazão da torneira para uma mesma abertura da válvula, reduzindo o consumo de água no equipamento. Nas edificações comerciais e públicas, segundo os autores, recomenda-se a instalação de torneiras de fechamento automático, tanto de funcionamento hidromecânico como com sensor de presença.

O consumo diário de água em uma torneira é função da frequência de uso, da duração dos acionamentos e da sua vazão. A frequência de uso e a duração do acionamento dependem fundamentalmente do comportamento dos usuários, enquanto a vazão é determinada pela tecnologia do equipamento e por algumas características físicas do sistema hidráulico, como a pressão no ponto de utilização (FIDAR; MEMON; BUTLER, 2016). No caso das torneiras convencionais, os usuários controlam a duração do acionamento e a vazão do equipamento, que varia conforme a abertura da válvula da torneira. Nas torneiras de funcionamento hidromecânico, os usuários apenas acionam a torneira e o fechamento ocorre automaticamente após determinado tempo de acionamento. Desta forma, o fato do usuário não controlar a vazão e o ciclo de tempo de abertura e fechamento ao acionar 
a torneira resultam em uma redução significativa do consumo de água (SAUTCHUK et al., 2005).

Alexandre, Kalbusch e Henning (2017) concluíram que a substituição de torneiras convencionais por modelos de funcionamento hidromecânico em um bloco de salas de aula de um campus universitário provocou uma redução de 20,43\% no consumo de água das torneiras. Kalbusch e Ghisi (2016) verificaram que as torneiras de funcionamento hidromecânico instaladas em um campus universitário consomem 26\% menos água quando comparadas às torneiras convencionais. Demanboro et al. (2015) compararam duas torneiras de lavatório instaladas em uma Universidade e determinaram que o modelo convencional apresentou consumo $27 \%$ maior do que o de fechamento automático. Proença e Ghisi (2013), ao analisarem edifícios comerciais, constataram que a substituição de torneiras de lavatório convencionais por modelos de funcionamento hidromecânico proporcionaria redução de 2,7\% a 15,4\% no consumo total de água das edificações.

A redução do consumo total de água proporcionada pela substituição de equipamentos hidrossanitários convencionais por economizadores está diretamente relacionada aos usos finais da água na edificação e aos hábitos dos usuários. Os usos finais variam muito entre edifícios porque dependem de vários fatores, como cultura, padrão de vida dos usuários e clima local (PROENÇA; GHISI, 2010). Portanto, mesmo que a instalação de equipamentos economizadores proporcione economia de água sem a necessidade de alterar o comportamento dos usuários (FIDAR; MEMON; BUTLER, 2010), a diferença entre os usos finais da água faz com que esta medida proporcione economias de água diferentes conforme a edificação em que for adotada.

Fidar, Memon e Butler (2016) realizaram um estudo comparativo entre torneiras convencionais e modelos de fechamento automático em relação ao uso da água. Os autores constataram que há uma forte relação entre a duração do acionamento e o consumo de água em uma torneira. Portanto, é importante que o tempo de acionamento das torneiras de funcionamento hidromecânico tenha duração adequada para que a economia de água proporcionada pela substituição de equipamentos convencionais por economizadores seja significativa. O ciclo de acionamento de uma torneira de funcionamento hidromecânico não deve ser muito curto, para evitar que o usuário tenha que acionar a torneira mais de uma vez para executar uma única atividade, e nem muito longo, impedindo que ele termine de usar a torneira e ela permaneça acionada. A NBR 13713 (ABNT, 2009) estabelece que o tempo de ciclo de aparelhos automáticos para lavatório (torneiras de funcionamento hidromecânico) deve ser entre quatro e dez segundos.

Fidar, Memon e Butler (2016) também verificaram que a relação entre a vazão de uma torneira e o seu consumo de água é menos evidente, uma vez que elevados consumos podem ocorrer mesmo em equipamentos com baixa vazão. Comparando equipamentos que tenham o mesmo tempo médio de acionamento, naturalmente o que tiver menor vazão consumirá menos água. No entanto, segundo os autores, o consumo de água em uma torneira está mais associado à duração do seu acionamento do que à sua vazão.

Pimentel-Rodrigues e Silva-Afonso (2012) atentam para a importância de garantir o conforto dos usuários mesmo com o uso de equipamentos economizadores de água. Segundo os autores, a redução da vazão das torneiras algumas vezes pode prejudicar essa condição. A NBR 13713 (ABNT, 2009) estabelece que a vazão mínima de torneiras de funcionamento hidromecânico deve ser 0,04 L/s.

\section{Método}

Esse estudo foi realizado no campus do Centro de Ciências Tecnológicas da Universidade do Estado de Santa Catarina (UDESC), localizado em Joinville, SC. O campus atende os alunos de nove cursos de graduação e dez cursos de pós-graduação. A pesquisa foi desenvolvida no banheiro masculino do bloco D do campus, no qual há apenas duas torneiras instaladas, uma delas convencional com registro de pressão (torneira T.1) e outra com funcionamento hidromecânico (torneira T.2), conforme é apresentado na Figura 1. O bloco em questão possui salas de aula e laboratórios de física, química e informática e é utilizado por alunos, professores, funcionários e visitantes de segunda a sábado, sendo que aos sábados o fluxo de pessoas na universidade é menor. Nos domingos e feriados escolares, apenas a equipe de segurança do campus usa os banheiros deste bloco. O banheiro onde foi realizada a pesquisa é abastecido a partir de um reservatório superior situado na cobertura do prédio.

A pesquisa foi realizada de modo a constatar as reais condições de operação das torneiras. Assim, não foram realizadas intervenções como troca dos equipamentos, ajuste de vazão, ou correção de vazamentos, sendo, portanto, um levantamento amostral. As torneiras T.1 e T.2 são de marcas diferentes e nenhum dos dois modelos é certificado pelo INMETRO (INSTITUTO..., 2018). Contudo, os dois fabricantes estão avaliados como qualificados segundo a Classificação das Empresas no Programa Brasileiro da Qualidade e 
Produtividade do Habitat (PBQP-H) (TECNOLOGIA..., 2017a, 2017b). Apenas a torneira T.2 possui arejador.

\section{Análise das condições de operação das torneiras}

Inicialmente foram analisadas as condições de operação das duas torneiras, observando-se a vazão de operação, o tipo de jato e a presença de vazamentos ou outros defeitos nos equipamentos. A vazão foi determinada pelo método gravimétrico, utilizando um Becker, uma balança de precisão e um cronômetro. Esse método consiste em coletar a massa de água escoada pelo equipamento em um determinado intervalo de tempo. O procedimento foi repetido três vezes para cada torneira e a vazão adotada para análise foi a média aritmética dos três valores. Para a torneira convencional, mediu-se a vazão máxima, isto é, com sua válvula totalmente aberta. No caso da torneira de funcionamento hidromecânico, foi feita a medição da vazão regulada na sua instalação.

A vazão média dos equipamentos foi comparada com o valor de referência apresentado pela NBR 5626 (ABNT, 1998) para torneiras de lavatório $(0,15 \mathrm{~L} / \mathrm{s})$. No caso da torneira de funcionamento hidromecânico, sua vazão também foi comparada com o valor mínimo estabelecido pela NBR 13713 (ABNT, 2009) para torneiras de lavatório com ciclo de fechamento automático $(0,04 \mathrm{~L} / \mathrm{s})$.

Foi verificado também se o tempo de acionamento da torneira de funcionamento hidromecânico respeitava o intervalo de quatro a dez segundos estabelecido pela NBR 13713 (ABNT, 2009). A medição do tempo de acionamento foi feita com o cronômetro e também foi repetida três vezes. O tempo de acionamento utilizado para comparação foi a média aritmética dos três valores.
Multiplicando os valores da vazão média e do tempo médio de acionamento referentes à torneira de funcionamento hidromecânico, obteve-se o volume de água gasto em um ciclo de acionamento. Desta forma, foi possível analisar se este valor era menor do que o volume máximo que pode ser disponibilizado em um ciclo de funcionamento $(1,2$ L) estipulado pela NBR 13713 (ABNT, 2009).

\section{Coleta de dados}

Após a análise das condições de operação das torneiras, iniciou-se a fase de coleta de dados. Foram instalados nas ligações flexíveis dos dois lavatórios do banheiro sensores de fluxo de água modelo YF-S201. Esse modelo de sensor é utilizado para medir o volume de água que passa por uma tubulação. Quando há fluxo de água no sensor, este gera pulsos proporcionais à vazão, e com isso é determinado o volume de água que passa pela tubulação em que o sensor estiver instalado. Segundo informações do fabricante, a faixa de vazão em que esse sensor trabalha é de 1 a $30 \mathrm{~L} / \mathrm{min}$ e sua precisão é de 10\% (YIFA..., 2018). Foram feitas medições para verificar a exatidão do equipamento e os erros encontrados entre o volume medido pelo sensor e o coletado e calculado por meio do método gravimétrico foram de $3 \%$ para as duas torneiras.

Os sensores estavam ligados a um data-logger que registrava o volume de água consumido em cada torneira e a quantidade de vezes que estas eram acionadas. Desta forma, o equipamento usado para a coleta de dados exercia função de hidrômetro e contador de eventos. Os dados eram registrados em um cartão de memória em intervalos de dez minutos e posteriormente eram agrupados por dias para que fossem analisados o volume e o número de acionamentos diários das torneiras.

\section{Figura 1 - Torneiras instaladas no banheiro masculino do bloco D do campus do Centro de Ciência e Tecnologia da UDESC}

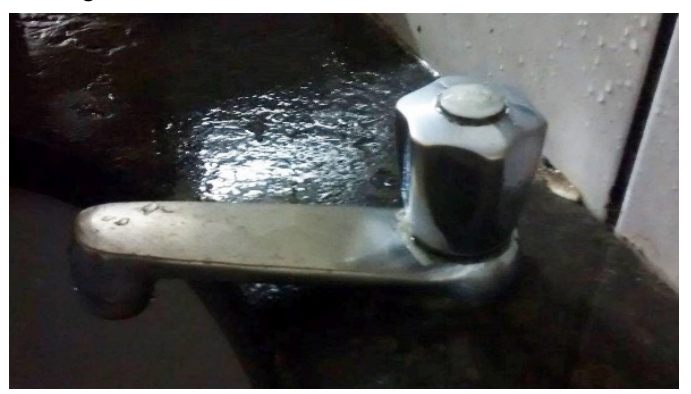

(a) Torneira convencional (T.1)

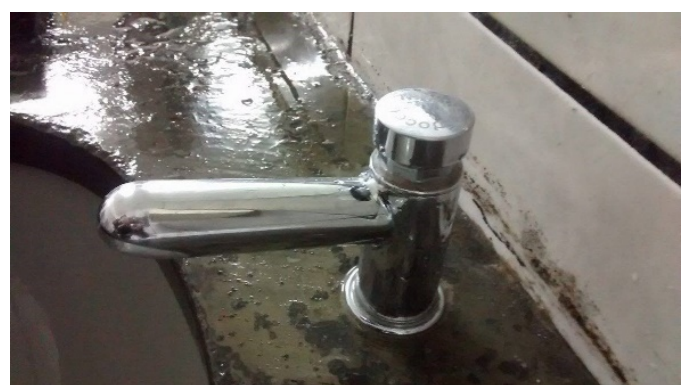

(b) Torneira de funcionamento hidromecânico

(T.2) 
As medições foram feitas entre 11 de março de 2016 e 03 de julho de 2016. Não foram considerados os finais de semana e os feriados escolares na análise dos dados, já que nesses dias o uso das torneiras é muito menor e isso poderia interferir nos resultados. Em três dias ocorreram falhas no equipamento, que não registrou a leitura em alguns horários. Essas medições também foram descartadas. Ao final, restaram registros de 72 dias para análise. Este estudo se caracteriza como longitudinal e prospectivo, com o período de análise englobando um semestre letivo completo.

\section{Análise estatística}

Foram analisadas três variáveis para cada torneira: volume diário consumido, número de acionamentos diário e volume médio por acionamento diário (obtido pela divisão do volume pelo número de acionamentos).

Primeiro foi feita uma análise exploratória dos dados, com a determinação de algumas medidas descritivas (mínimo, máximo, média e desvio padrão) das variáveis. Foram calculadas também as medidas descritivas do consumo de água, número de acionamentos e volume por acionamento das torneiras em cada mês do período de medições para identificar uma possível diferença no consumo e no número de acionamentos em diferentes épocas do ano. Foram construídos os boxplots de cada amostra para verificar sua simetria ou assimetria e identificar a presença de valores discrepantes ou outliers (WALFISH, 2006). Foi verificada a normalidade de todas as amostras por meio do teste de Shapiro-Wilk. A verificação da normalidade é essencial para a aplicação de determinados testes estatísticos (BARBETTA; REIS; BORNIA, 2010).

Para comparar as torneiras em relação a cada uma das três variáveis e comparar os dados de cada equipamento mês a mês, utilizou-se o teste de Mann-Whitney. Este é um teste não paramétrico utilizado quando se deseja verificar se duas amostras independentes foram extraídas de populações com a mesma mediana. O teste de Mann-Whitney é uma opção para comparação de dois grupos quando não é possível aplicar o teste $t$ de Student para comparação de médias entre amostras independentes (BARBETTA; REIS; BORNIA, 2010). A análise da variabilidade dos dados das torneiras referente às três variáveis foi feita a partir do teste não paramétrico de Fligner para verificar a homogeneidade das variâncias (CONOVER; JOHNSON; JOHNSON, 1981). Técnicas não paramétricas podem ser aplicadas se os dados não satisfazem as suposições necessárias pelos testes paramétricos, como por exemplo a suposição de normalidade (BARBETTA; REIS; BORNIA, 2010).

A determinação das medidas descritivas de cada amostra e a aplicação dos testes estatísticos foi feita após o tratamento dos outliers. Os conjuntos de dados que continham valores discrepantes tiveram os mesmos substituídos por uma medida de tendência central, nesse caso, pelo valor da mediana da amostra correspondente (BURKE, 2001). Optouse por substituir os outliers pela mediana porque essa medida é menos afetada por valores extremos da amostra do que a média (BARBETTA; REIS; BORNIA, 2010).

A análise estatística foi feita com a utilização do programa computacional R (R CORE..., 2016). O nível de significância adotado para todos os testes estatísticos foi igual a $5 \%(\alpha=0,05)$. Foram considerados significativos os resultados com probabilidade de significância (p-valor) menores que o nível de significância adotado.

\section{Análise do desperdício de água na torneira convencional}

Durante a etapa da coleta de dados, analisando os dados coletados a cada dez minutos, notou-se que em algumas leituras a torneira T.1 apresentava um volume de água consumido muito elevado para o número de acionamentos registrado no intervalo de tempo. Por isso, investigou-se a ocorrência de desperdício nessa torneira decorrente do uso excessivo de água ou do mau fechamento da sua válvula. Essa análise foi feita para todos os dados registrados a cada dez minutos durante todo o período de medições, considerando também fins de semana, feriados escolares e dias em que ocorreram falhas pontuais no equipamento.

Foi considerado que em determinada leitura ocorria desperdício de água, seja por uso excessivo do usuário ou pelo mau fechamento da válvula, quando ela resultava em um volume por acionamento superior à média mais três desvios padrão do volume por acionamento diário desse equipamento.

\section{Resultados e discussões}

\section{Análise das condições de operação das torneiras}

Na inspeção visual feita nas torneiras foi verificado que ambas tinham jato d'água linear e não possuíam qualquer tipo de vazamento ou outro defeito. A torneira T.1 apresentou vazão para abertura total de 0,13 L/s, muito próxima ao valor recomendado pela NBR 5626 (ABNT, 1998) para torneiras de lavatório $(0,15 \mathrm{~L} / \mathrm{s})$. Já T.2 apresentou uma vazão bem inferior, 0,03 L/s. Apesar de significar menor 
consumo de água por acionamento, a vazão de T.2, por ser demasiadamente baixa, poderia ser considerada desconfortável pelos usuários, já que também era inferior à vazão mínima estabelecida pela NBR 13713 (ABNT, 2009) para torneiras de funcionamento hidromecânico $(0,04 \mathrm{~L} / \mathrm{s})$.

Foram analisados a duração do acionamento de T.2 e o volume de água gasto por acionamento. O tempo médio de acionamento verificado para a torneira T.2 foi 9,06 s, atendendo à especificação da NBR 13713 (ABNT, 2009). A duração do acionamento desse equipamento é considerada suficiente para que o usuário faça suas atividades sem a necessidade de acionar a torneira mais de uma vez. O volume de água gasto, em média, por acionamento desta torneira é de 301,18 mL, bem inferior ao máximo estabelecido pela NBR 13713 (ABNT, 2009). Considerando um acionamento com a mesma duração do ciclo médio de funcionamento da torneira T.2 (9,06 s), a torneira T.1 gastaria cerca de $1177,80 \mathrm{~mL}$ por acionamento, volume quase quatro vezes maior do que o consumido pela torneira T.2.

\section{Análise estatística}

Durante os 72 dias de medição, as duas torneiras instaladas no banheiro masculino do bloco D foram acionadas 28.687 vezes (49,6\% dos acionamentos em T.1 e 50,4\% em T.2) e consumiram 18.024,19 L de água (74,2\% consumido em T.1 e $25,8 \%$ em T.2). Nesse período, foram registrados dados diários de volume, número de acionamentos e volume por acionamento das duas torneiras, os quais são apresentados nas Figuras 2, 3 e 4.

Os dados de volume diário consumido obtidos para T.2 são bem inferiores quando comparados aos de T.1 (Figura 2). Enquanto para T.2 o volume diário consumido não ultrapassou os $100 \mathrm{~L}$ em nenhum dia, para T.1 o volume foi maior que $150 \mathrm{~L}$ na maioria deles, havendo dois dias em que o volume consumido superou 350 L. Contudo, vale ressaltar que a vazão de T.2 era inferior à estabelecida pela NBR 13713 (ABNT, 2009) para torneiras de funcionamento hidromecânico, podendo o uso dessa torneira ser desconfortável aos usuários por sua vazão ser extremamente baixa. Essa característica pode ter contribuído para o aumento da diferença de consumo entre as duas torneiras.

Não há grande diferença, em média, entre o número de acionamentos das torneiras T.1 e T.2 (Figura 3). Os dias em que ocorreu o número de acionamentos máximo para as duas torneiras coincidem com o dia em que houve o consumo de água máximo (31 de abril de 2016). O dia com menor número de acionamentos para T.2 também é o mesmo em que a torneira consumiu menor volume de água.

Figura 2 - Dados diários de volume de água consumido nas torneiras convencional (T.1) e de funcionamento hidromecânico (T.2)

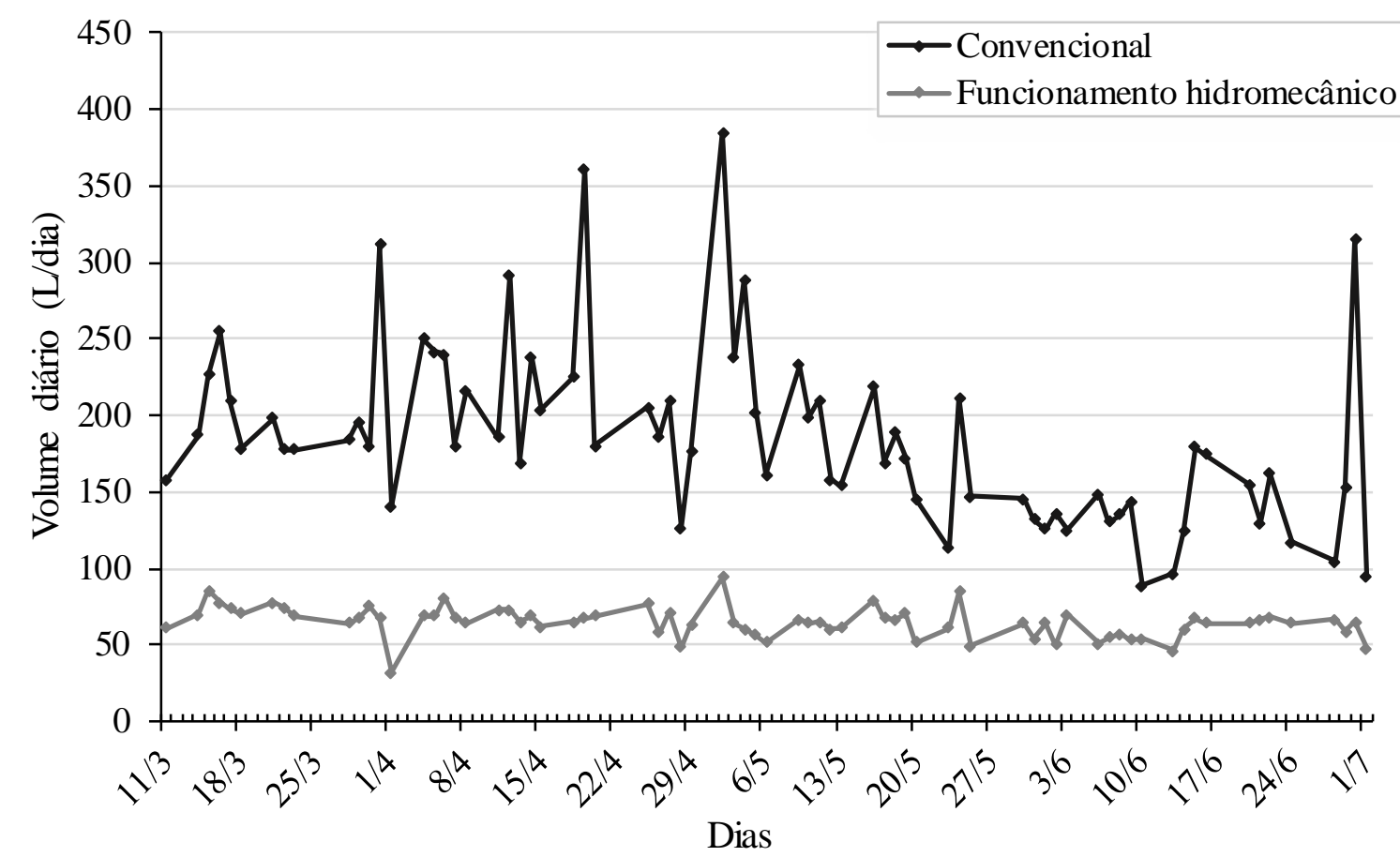


Figura 3 - Dados diários de número de acionamentos nas torneiras convencional (T.1) e de funcionamento hidromecânico (T.2)

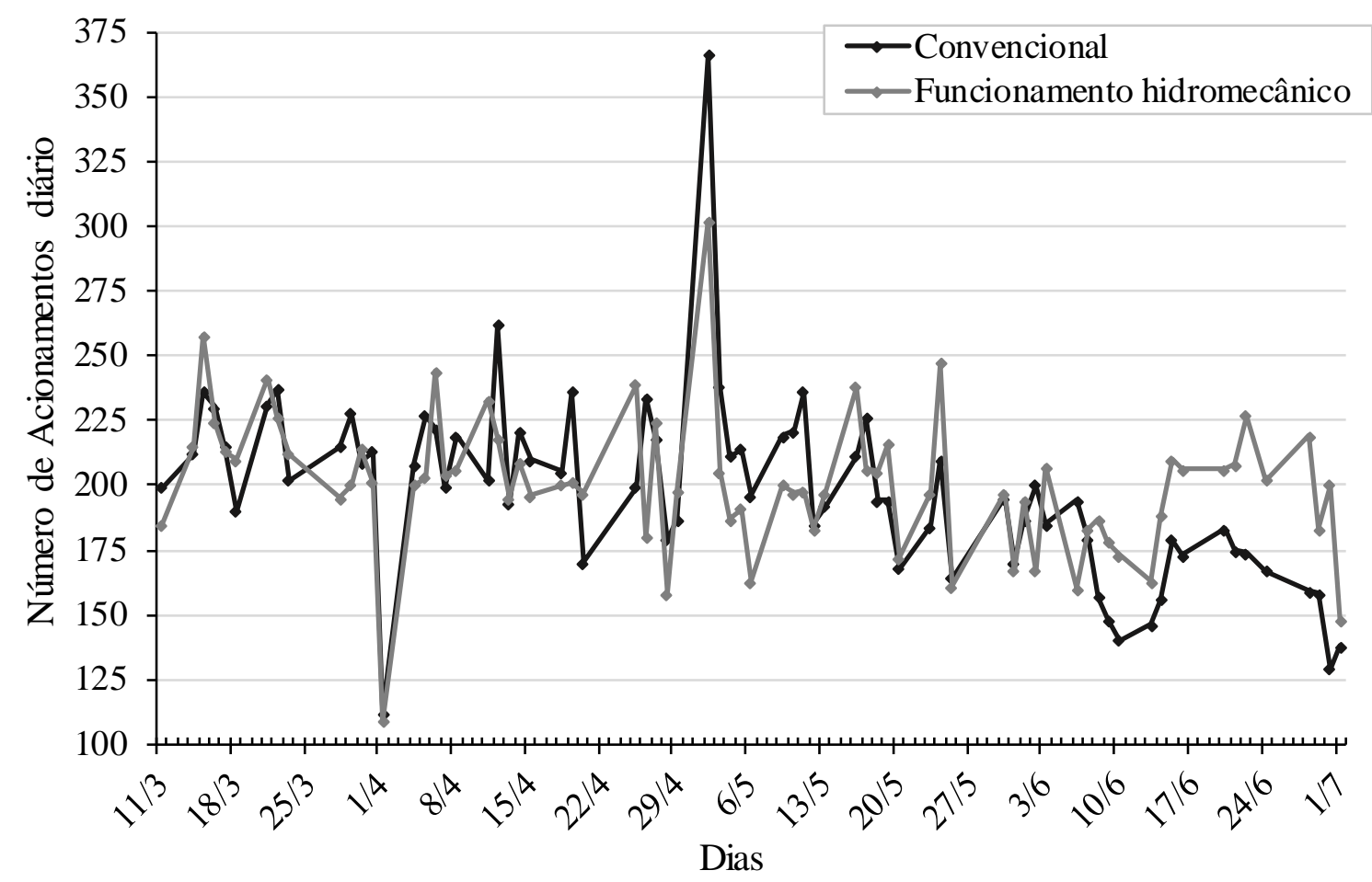

Figura 4 - Dados diários de volume por acionamento nas torneiras convencional (T.1) e de funcionamento hidromecânico (T.2)

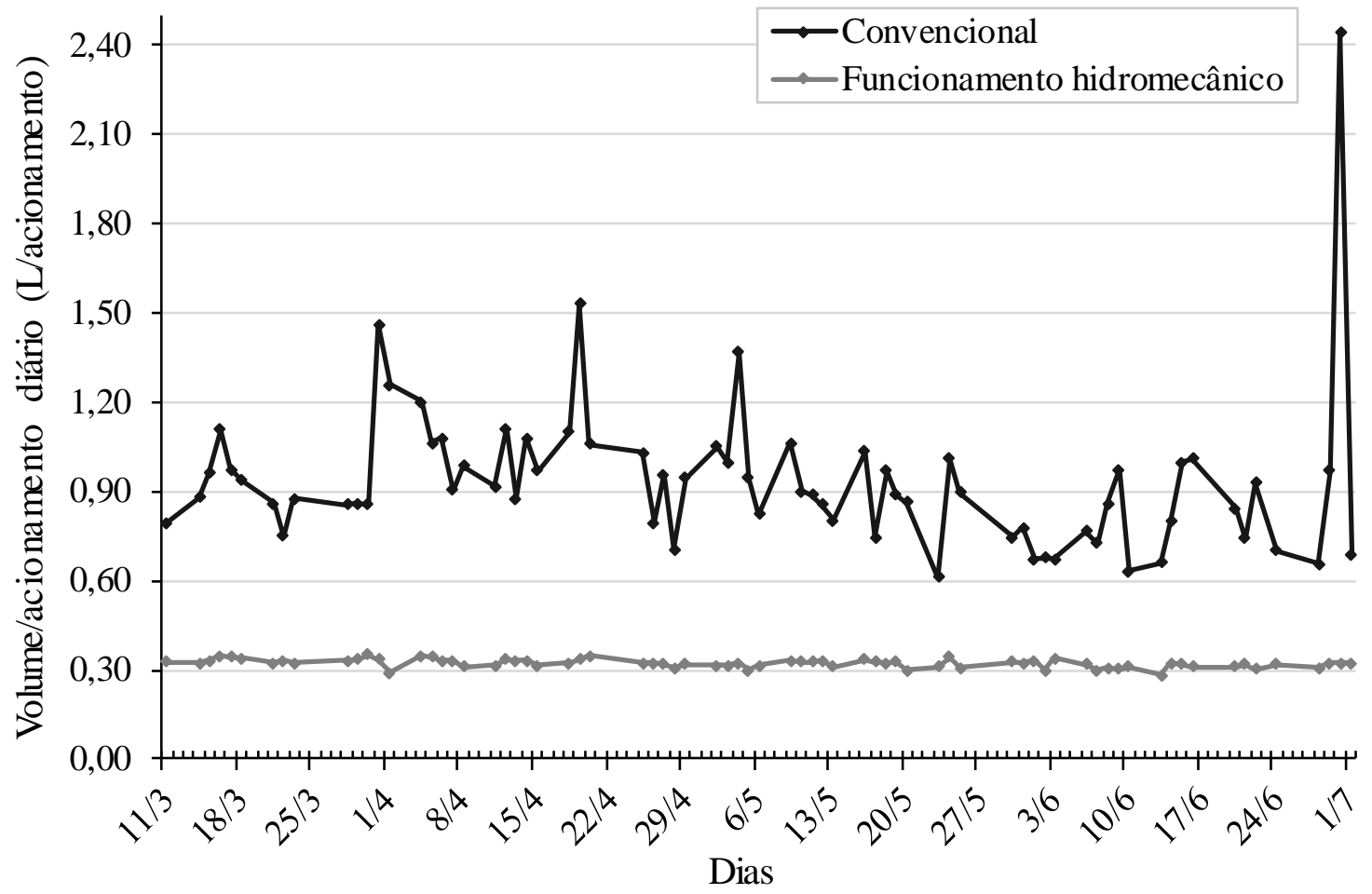


Comparando a variável volume por acionamento diário das torneiras (Figura 4), constata-se que os dados de T.2 variam muito pouco. Esse comportamento já era esperado, pois nas torneiras de funcionamento hidromecânico a duração do acionamento e a vazão não são reguladas pelo usuário. Já para T.1, além dos dados serem mais dispersos, os valores de volume por acionamento diário são maiores quando comparados aos de T.2 (maior do que o dobro na maioria dos casos), com destaque para a observação do dia 30 de junho de 2016, quando o volume consumido por acionamento, em média, ficou próximo de 2,40 L.

Os boxplots obtidos para cada uma das amostras analisadas são apresentados nas Figuras 5, 6 e 7. Nesses diagramas é possível verificar quais dados de cada amostra são considerados outliers. Comparando os boxplots das duas torneiras, nota-se que T.1 apresenta a forma de distribuição dos dados mais assimétrica que de T.2.

Com a construção dos boxplots, verificou-se que cinco das seis amostras analisadas apresentavam outliers. Apenas a amostra de volume por acionamento diário da torneira T.2 não apresentou nenhum valor discrepante. Antes da aplicação dos testes estatísticos e da determinação das medidas descritivas, os outliers foram substituídos pela mediana de cada amostra.

Aplicando o teste de Shapiro-Wilk, identificou-se que apenas os dados referentes ao volume por acionamento diário de T.2 não apresentaram distribuição normal ( $p$-valor $=0,0060)$. Contudo, as demais amostras da torneira T.2 obtiveram p-valor muito próximo ao nível de significância adotado (pvalor $=0,0560$ para volume diário consumido e $\mathrm{p}$ valor $=0,0640$ para número de acionamentos diário). Portanto, optou-se por utilizar técnicas não paramétricas nesse estudo, pois:

[...] os procedimentos não paramétricos têm desempenho tão bom quanto seus concorrentes paramétricos quando a distribuição for normal e frequentemente oferecem uma melhora considerável sob condições não normais [...]. (DEVORE, 2006, p. 580).

\section{Figura 5 - Boxplots dos dados de volume diário consumido pelas torneiras convencional (T.1) e de} funcionamento hidromecânico (T.2)

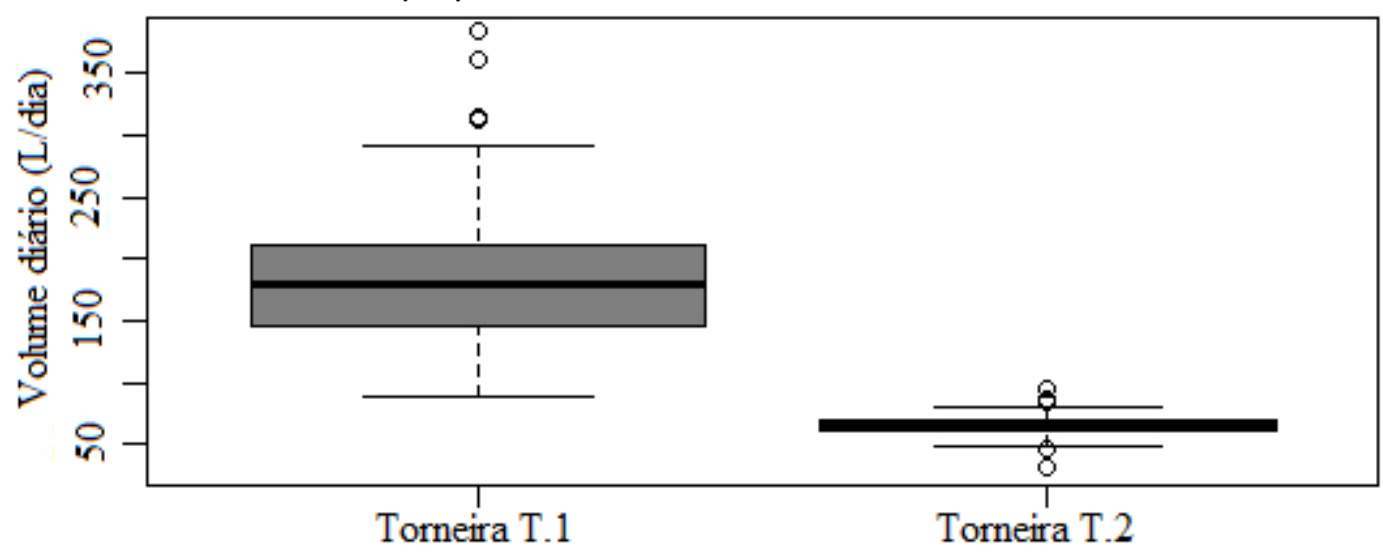

Figura 6 - Boxplots dos dados de número de acionamentos diário nas torneiras convencional (T.1) e de funcionamento hidromecânico (T.2)

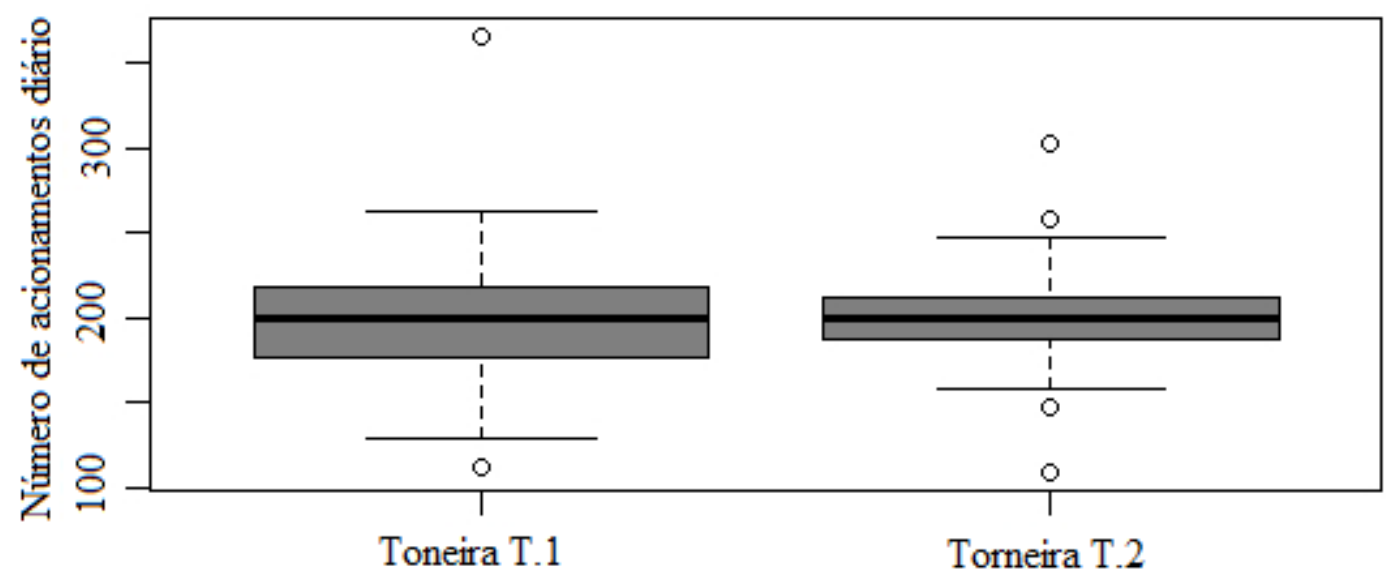


Figura 7 - Boxplots dos dados de volume por acionamento diário para as torneiras convencional (T.1) e de funcionamento hidromecânico (T.2)

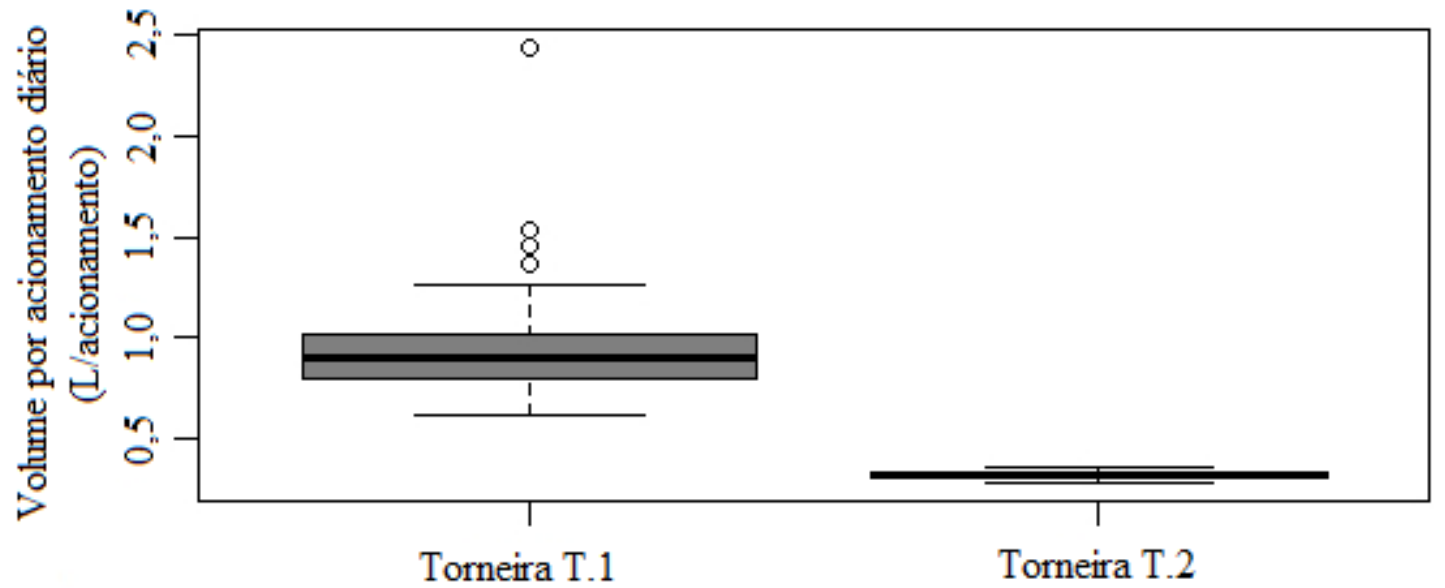

As medidas descritivas obtidas para o volume, número de acionamentos e volume por acionamento de cada uma das torneiras para todo o período de medição são apresentadas na Tabela 1.

As médias do volume diário consumido e do volume por acionamento diário para a torneira T.2 foram, respectivamente, 63,5\% e 64,0\% menores do que para T.1, sendo essa diferença significativa de acordo com o teste de Mann-Whitney (p-valor < 2,2e-16 para as duas variáveis). Esse resultado já era esperado, uma vez que a torneira de funcionamento hidromecânico, por ser um equipamento economizador de água, tem a característica de gastar menos água por acionamento do que uma torneira convencional, o que resulta em um menor volume de água consumido. Além disso, no caso desse estudo, a torneira T.2 apresentava vazão bastante inferior à vazão de T.1, fazendo com que a diferença de consumo entre as duas torneiras fosse maior. Segundo informações da equipe de limpeza do banheiro, como não havia torneira específica para essa atividade no banheiro onde foi feita a pesquisa, T.1 era utilizada para a limpeza, o que também contribui para elevar o consumo de água diário dessa torneira.

Ao contrário desses resultados, em uma pesquisa feita por Fidar, Memon e Butler (2016) para comparar uma torneira convencional e uma torneira com acionamento por sensor, a média do volume por acionamento para a torneira de fechamento automático foi ligeiramente superior à média para a torneira convencional (0,67 L/acionamento e 0,70 L/acionamento, respectivamente). Demanboro et al. (2015) compararam uma torneira convencional a outra acionada por sensor e verificaram que o consumo de água por acionamento do modelo convencional também era menor $(0,8$ L/acionamento para a torneira convencional e 0,9 L/acionamento para a torneira com sensor). No estudo de Fidar, Memon e Butler (2016), a vazão das torneiras era semelhante, mas o acionamento do equipamento convencional era, em média, dois segundos mais curto ( $7 \mathrm{~s}$ contra $9 \mathrm{~s}$ da torneira com sensor). Isso resultou em um consumo total de água maior para a torneira economizadora de água. Na pesquisa de Demanboro et al. (2015), a vazão da torneira com sensor era muito maior $(10,4 \mathrm{~L} / \mathrm{min})$ que a da torneira convencional (3,5 L/min). Contudo, o elevado tempo médio de acionamento da torneira convencional fez com que este equipamento tivesse um consumo total de água maior do que o modelo com fechamento automático. Esses estudos mostram que a simples substituição de uma torneira convencional por um modelo de fechamento automático nem sempre é suficiente para reduzir o consumo de água. É preciso que o equipamento economizador esteja bem regulado, com vazão e tempo de acionamento adequados às atividades que ele irá atender.

A média do número de acionamentos diário de T.1 e T.2 é semelhante. Esse resultado concorda com o obtido por Demanboro et al. (2015), que verificaram que a média dos acionamentos diários dos dois aparelhos avaliados também era muito próxima (seis acionamentos para a torneira acionada por sensor e sete acionamentos para a torneira convencional).

A aplicação do teste de Mann-Whitney confirmou que não há diferenças significativas entre as duas torneiras para a variável número de acionamentos (p-valor $=0,5147)$. Nesta análise, buscava-se avaliar se havia preferência dos usuários por usar uma das duas torneiras. Por exemplo, T.1 estava instalada mais próxima à entrada do banheiro, o que poderia ser um motivo para essa torneira ser mais usada. Poderia haver também uma preferência por se utilizar T.1 pelo fato da vazão de T.2 ser muito baixa, fazendo com que seu uso pudesse ser 
considerado desconfortável por algumas pessoas. A torneira T.2, por ser de funcionamento hidromecânico, poderia ser considerada mais higiênica do que T.1 (convencional), uma vez que o usuário não precisa tocar sua válvula após ter feito a lavagem das mãos, fator que poderia contribuir para um maior uso de T.2. Além disso, poderia se esperar que o usuário optasse por T.2 pelo fato de ser uma torneira economizadora, denotando práticas de conservação de água. No entanto, com a aplicação do teste de Mann-Whitney, concluiu-se que não há diferença no número de acionamentos diário das duas torneiras. Portanto, em geral não há preferência dos usuários desse banheiro por usar uma ou outra torneira.

Esse resultado também permite concluir que, como o número de acionamentos diário das duas torneiras é semelhante, a diferença entre o volume diário consumido é função da diferença entre os volumes por acionamento das duas torneiras. Portanto, a torneira com menor volume por acionamento, nesse caso a de funcionamento hidromecânico, consome menos água. Nas torneiras de funcionamento hidromecânico esse valor é mais constante, enquanto nas convencionais ele pode ser muito variável porque nesse modelo de equipamento o usuário tem controle da vazão e do tempo de acionamento da torneira.

Com relação à variabilidade, a torneira T.1 apresentou maior heterogeneidade nos dados para o volume diário consumido do que a T.2, sendo o desvio padrão para T.2 quase seis vezes menor do que o desvio padrão para T.1. Essas diferenças são significativas, de acordo com os resultados do teste Fligner (p-valor $=6,326 \mathrm{e}-12)$, e podem se dar pelo fato do usuário controlar a vazão e a duração do acionamento em T.1 e não controlar em T.2. O volume diário consumido por T.1 não é função apenas do número de acionamentos que houve no dia, mas também da duração e da vazão de cada um deles. Em T.2 há pouca diferença de volume de água consumido de um acionamento para outro, fazendo com que o volume diário consumido por T.2 seja determinado essencialmente pelo número de vezes que a torneira é acionada nesse período. Essa mesma relação é válida para a variável volume por acionamento diário das duas torneiras, visto que mesmo que os desvios padrão sejam baixos para ambas, o valor obtido para T.1 é significativamente maior do que o de T.2 (p-valor = 9,385e-16).

A média e o desvio padrão dos dados diários de cada torneira, separados por mês, são apresentados na Tabela 2.

Tabela 1 - Medidas descritivas das amostras

\begin{tabular}{|c|c|c|c|c|c|}
\hline & Amostra & Mínimo & Máximo & Média & $\begin{array}{l}\text { Desvio } \\
\text { padrão }\end{array}$ \\
\hline T.1 & $\begin{array}{l}\text { Volume } \\
\text { Número de acionamentos } \\
\text { Volume por acionamento }\end{array}$ & $\begin{array}{l}88,26 \\
129,00 \\
0,61\end{array}$ & $\begin{array}{l}291,67 \\
262,00 \\
1,26\end{array}$ & $\begin{array}{l}176,53 \\
196,68 \\
0,89\end{array}$ & $\begin{array}{l}43,74 \\
27,72 \\
0,14 \\
\end{array}$ \\
\hline Т.2 & $\begin{array}{l}\text { Volume } \\
\text { Número de acionamentos } \\
\text { Volume por acionamento }\end{array}$ & $\begin{array}{l}47,81 \\
158,00 \\
0,28\end{array}$ & $\begin{array}{l}80,80 \\
247,00 \\
0,35\end{array}$ & $\begin{array}{l}64,39 \\
200,40 \\
0,32\end{array}$ & $\begin{array}{l}7,56 \\
20,11 \\
0,01\end{array}$ \\
\hline
\end{tabular}

Tabela 2 - Média e desvio padrão do volume diário de água consumido, número de acionamentos diário e volume por acionamento diário, separados por mês

\begin{tabular}{|c|c|c|c|c|c|c|c|c|c|}
\hline & \multirow[b]{2}{*}{ Amostra } & \multicolumn{2}{|c|}{ Março } & \multicolumn{2}{|c|}{ Abril } & \multicolumn{2}{|c|}{ Maio } & \multicolumn{2}{|c|}{ Junho } \\
\hline & & Média & $\begin{array}{l}\text { Desvio } \\
\text { padrão }\end{array}$ & Média & $\begin{array}{l}\text { Desvio } \\
\text { padrão }\end{array}$ & Média & $\begin{array}{l}\text { Desvio } \\
\text { padrão }\end{array}$ & Média & $\begin{array}{l}\text { Desvio } \\
\text { padrão }\end{array}$ \\
\hline \multirow{3}{*}{ T.1 } & Volume & 192,60 & 25,25 & 202,27 & 39,94 & 183,19 & 42,36 & 134,98 & 26,16 \\
\hline & Número de acionamentos & 216,69 & 14,82 & 210,00 & 21,72 & 201,35 & 21,27 & 166,35 & 19,75 \\
\hline & Volume por acionamento & 0,89 & 0,09 & 1,00 & 0,13 & 0,89 & 0,12 & 0,79 & 0,13 \\
\hline \multirow{3}{*}{ Т.2 } & Volume & 70,01 & 5,36 & 67,10 & 7,09 & 62,01 & 7,18 & 60,53 & 6,76 \\
\hline & Número de acionamentos & 201,46 & 14,71 & 205,53 & 20,04 & 196,35 & 21,85 & 193,05 & 18,65 \\
\hline & Volume por acionamento & 0,33 & 0,01 & 0,33 & 0,01 & 0,32 & 0,01 & 0,31 & 0,01 \\
\hline
\end{tabular}


Verificou-se que as torneiras consumiram mais água e foram mais utilizadas na estação quente (março) do que na fria (junho). Esse resultado concorda com as conclusões de Alexandre, Kalbusch e Henning (2017), que por meio de uma regressão linear múltipla verificaram que há uma tendência de o consumo de água em torneiras de lavatório ser maior para temperaturas do ar ambiente mais elevadas. A diferença no consumo entre esses dois períodos se mostrou significativa segundo o teste de Mann-Whitney (p-valor = 1,374e-05 para T.1 e p-valor $=0,0003514$ para T.2). O mesmo ocorreu para a variável número de acionamentos (p-valor $=3,139 \mathrm{e}-06$ para T.1 e pvalor $=0,01214$ para T.2). A variável volume por acionamento diário apresentou pouca variação ao longo dos meses para as duas torneiras.

\section{Análise do desperdício de água na torneira convencional}

Analisando os dados obtidos a cada dez minutos para a torneira T.1, verificou-se que em algumas observações ocorria um elevado consumo de água para a quantidade de acionamentos registrada. Notaram-se também alguns indícios de que às vezes a válvula da torneira não era fechada completamente pelos usuários após seu uso. De acordo com alguns usuários e pessoas responsáveis pela limpeza do banheiro onde foi realizada a pesquisa, T.1 várias vezes era encontrada aberta, gerando desperdício de água. Desta forma, analisaram-se os dados dessa torneira pontualmente para avaliar esses desperdícios.

A análise do desperdício de água foi feita com base em 6.186 leituras desta torneira, verificando se a razão volume por número de acionamentos era superior à média mais três desvios padrão dos dados de volume por acionamento diário desse equipamento.

Em 641 observações (10,4\%), o volume por acionamento foi superior ao limite estipulado. Portanto, nessas leituras supôs-se que ocorreu desperdício por uso excessivo de água pelos usuários ou pelo mau fechamento da válvula da torneira. Apenas dez dias dos 115 analisados não apresentaram nenhuma leitura com volume por acionamento acima desse limite, sendo que esses dias eram finais de semana ou feriados escolares, nos quais a utilização das torneiras do banheiro é menor.

Nestas 641 leituras, foram consumidos 4.699,83 L de água (33,0\% de todo o volume gasto em T.1 nos 115 dias de medição). Sabendo que esse volume consumido é referente a 1.226 acionamentos, nessas leituras consumiu-se, em média, 3,83 L/acionamento, valor quatro vezes maior do que a média do volume por acionamento diário de T.1. Se nos 1.226 acionamentos registrados nessas leituras o consumo fosse igual ao volume por acionamento médio diário da torneira T.1 (0,89 L/acionamento), seriam gastos 1.091,14 L de água, 76,8\% a menos do que realmente foi consumido.

No banheiro onde foi realizada a pesquisa não havia torneira para limpeza. Algumas vezes T.1 era utilizada também com essa finalidade segundo relatos da equipe que realizava esse serviço no banheiro, o que geraria maior consumo em algumas leituras feitas ao longo do dia. A equipe responsável pela limpeza do banheiro em questão informou que durante o período de realização da pesquisa esse serviço era feito entre 5 h e 6h30min. Dos 641 dados em que o volume por acionamento foi superior ao limite estipulado, 95 (14,8\%) ocorreram no horário de limpeza do banheiro. Assim, em 85,2\% das leituras acima do limite de três desvios padrão há fortes indícios de que houve consumo excessivo de água pelos usuários ou que a válvula da torneira tenha sido deixada aberta.

Os registros com uso excessivo de água feitos durante o horário de limpeza do banheiro correspondem a 1.016,55 L de água consumidos (7,1\% do volume gasto em T.1 em todos os dias de medição). Esse volume foi gasto em 172 acionamentos, o que resulta em uma média de 5,91 L por acionamento consumidos nessas leituras (seis vezes maior que a média de volume por acionamento diário de T.1).

Vale ressaltar que, independente do desperdício ter ocorrido em função do uso excessivo de água ou do mau fechamento da válvula da torneira, se esta fosse de funcionamento hidromecânico esses desperdícios não aconteceriam. Se a torneira convencional fosse substituída, o volume de água gasto em um acionamento seria praticamente constante ao longo do tempo, impedindo que fosse utilizada água em excesso em um acionamento de maior duração ou com vazão mais alta do que o necessário. Com essa substituição, também não haveria a possibilidade de a torneira ser deixada com a válvula aberta. Desta forma, impede-se o desperdício de água por essas razões ao substituir uma torneira convencional por outra de funcionamento hidromecânico.

\section{Considerações finais}

Neste estudo foi feita uma comparação entre duas torneiras de lavatório (uma convencional e outra de funcionamento hidromecânico) instaladas em um mesmo banheiro de um campus universitário. Analisaram-se dados diários de volume de água consumido, número de acionamentos e volume por 
acionamento de cada torneira com auxílio de técnicas estatísticas.

As médias do volume diário de água consumido e do volume por acionamento diário da torneira de funcionamento hidromecânico foram, respectivamente, $63,5 \%$ e $64,0 \%$ menores do que as da convencional. Contudo, verificou-se que a torneira economizadora tinha vazão inferior à estipulada pela NBR 13713 (ABNT, 2009) para esse modelo de equipamento, o que contribuiu para que a diferença entre esses valores fosse maior.

O resultado da aplicação de testes estatísticos confirmou que a diferença existente entre as duas torneiras em relação às variáveis volume de água consumido e volume por acionamento é significativa, e permitiu concluir que não há diferença em relação ao número de acionamentos. Isso indica que não há preferência dos usuários do banheiro onde foi feito o estudo por utilizar um dos modelos de torneira.

Analisando pontualmente os dados coletados para a torneira convencional, notaram-se indícios de que havia desperdício de água decorrente do mau fechamento da válvula dessa torneira ou do uso excessivo de água pelos usuários. Esse desperdício seria evitado caso a torneira convencional fosse substituída por outra de funcionamento hidromecânico porque esse modelo de torneira apresenta fechamento automático e não permite que o usuário controle a vazão e a duração do ciclo de funcionamento do equipamento. Assim, verificouse que a torneira de funcionamento hidromecânico avaliada neste estudo não gera economia de água apenas por consumir um volume menor do que a convencional, mas também por impedir a ocorrência de perdas provenientes do mau fechamento da válvula do equipamento ou do uso excessivo de água pelos usuários.

A principal limitação do estudo foi a sua aplicação a apenas duas torneiras, o que impede que esses resultados sejam estendidos a outras situações. Além disso, a vazão do modelo de funcionamento hidromecânico estava abaixo do valor recomendado pelas normas técnicas, o que interferiu na comparação do consumo diário e do consumo por acionamento entre os dois equipamentos. A utilização do método gravimétrico pode ter influenciado nos resultados obtidos para vazão das torneiras, pois esse procedimento é menos preciso do que equipamentos específicos, como medidores eletrônicos de vazão. Para trabalhos futuros, sugerese que também seja medida a duração dos acionamentos nos dois equipamentos para verificar se o tempo médio de abertura das torneiras convencionais é realmente maior do que nos modelos de funcionamento hidromecânico.

\section{Referências}

ALEXANDRE, A. C.; KALBUSCH, A.; HENNING, E. Avaliação do Impacto da Substituição de Equipamentos Hidrossanitários Convencionais Por Equipamentos Economizadores no Consumo de Água. Engenharia Sanitaria e Ambiental, v. 22, n. 5, p. 1005-1015, 2017. ASSOCIAÇÃO BRASILEIRA DE NORMAS TÉCNICAS. NBR 13713: instalações hidráulicas prediais: aparelhos automáticos acionados mecanicamente e com ciclo de fechamento automático: requisitos e métodos de ensaio. Rio de Janeiro, 2009.

\section{ASSOCIAÇÃO BRASILEIRA DE NORMAS} TÉCNICAS. NBR 5626: instalação predial de água fria. Rio de Janeiro, 1998.

BARBETTA, P. A.; REIS, M. M.; BORNIA, A. C. Estatística Para Cursos de Engenharia e Informática. 3. ed. São Paulo: Atlas, 2010.

BURKE, S. Missing Values, Outliers, Robust Statistics \& Non Parametric Methods. LC-GC Europe Online Supplement, Statistics \& Data Analysis, v. 2, p. 19-24, 2001.

CONOVER, W. J.; JOHNSON, M. E.; JOHNSON, M. M. A Comparative Study of Tests for Homogeneity of Variances, with Applications to the Outer Continental Shelf Bidding Data.

Technometrics, v. 23, n. 4, p. 351-361, 1981.

DEMANBORO, A. C. et al. Avaliação do Consumo de Água em Torneiras em Ambiente Universitário. Ambiente Construído, Porto Alegre, v. 15, n. 3, p. 135-143, jul./set. 2015.

DEVORE, J. L. Probabilidade e Estatística Para Engenharia e Ciências. 6 ed. São Paulo: Thomson, 2006.

FIDAR, A. M.; MEMON, F. A.; BUTLER, D. Performance Evaluation of Conventional and Water Saving Taps. Science of The Total Environment, v. 541, p. 815-824, 2016.

FIDAR, A.; MEMON, F. A.; BUTLER, D. Environmental Implications of Water Efficient Microcomponents in Residential Buildings.

Science of The Total Environment, v. 408, n. 23, p. 5828-5835, 2010.

GHISI, E.; FERREIRA, D. F. Potential For Potable Water Savings by Using Rainwater and Greywater in a Multi-Storey Residential Building in Southern Brazil. Building and Environment, v. 42, n. 7, p. 2512-2522, 2007. 
INSTITUTO NACIONAL DE METROLOGIA, QUALIDADE E TECNOLOGIA. Produtos Certificados. Disponível em:

$<$ http://www.inmetro.gov.br/prodcert/certificados/l ista.asp>. Acesso em: 05 mar. 2018.

JORGENSEN, B.; GRAYMORE, M.; O’TOOLE, K. Household Water Use Behavior: an integrated model. Journal of Environmental Management, v. 91, n. 1, p. 227-236, 2009.

KALBUSCH, A.; GHISI, E. Comparative LifeCycle Assessment of Ordinary and Water-Saving Taps. Journal of Cleaner Production, v. 112, p. 4585-4593, 2016.

KAMMERS, P. C.; GHISI, E. Usos Finais de Água em Edifícios Públicos Localizados em Florianópolis, SC. Ambiente Construído, Porto Alegre, v. 6, n. 1, p. 75-90, 2006.

KELLY, D. A. Labelling and water conservation: A European perspective on a global challenge. Building Services Engineering Research and Technology, v. 36, n. 6, p. 643-657, 2015.

MARINOSKI, A. K.; ANDRADE, M. Componentes Hidráulicos Economizadores de Água. In: LAMBERTS, R. et al. Casa Eficiente: uso racional da água. Florianópolis: UFSC/LabEEE, 2010.

MEIRELES, I. et al. User Preferences and Water Use Savings Owing to Washbasin Taps Retrofit: a case study of the DECivil building of the University of Aveiro. Environmental Science and Pollution Research, p. 1-11, 2017.

MILLOCK, K.; NAUGES, C. Household Adoption of Water-Efficient Equipment: the role of socio-economic factors, environmental attitudes and policy. Environmental and Resource Economics, v. 46, n. 4, p. 539-565, 2010.

MOSTAFAVI, N.; GÁNDARA, F.; HOQUE, S. Residential Water Consumption Modeling in the Integrated Urban Metabolism Analysis Tool (IUMAT). Resources, Conservation and Recycling, v. 131, p. 64-74, 2018.

MUTHUKUMARAN, S.; BASKARAN, K.; SEXTON, N. Quantification of Potable Water Savings by Residential Water Conservation and Reuse: a case study. Resources, Conservation and Recycling, v. 55, n. 11, p. 945-952, 2011.

PIMENTEL-RODRIGUES, C.; SILVA-AFONSO, A. Water Efficiency of Products: comfort limits. In: INTERNATIONAL SYMPOSIUM ON WATER SUPPLY AND DRAINAGE FOR BUILDINGS, 38., Edimburgo, 2012.

Proceedings... Edimburgo, 2012.
PROENÇA, L. C.; GHISI, E. Assessment of Potable Water Savings in Office Buildings Considering Embodied Energy. Water Resources Management, v. 27, n. 2, p. 581-599, 2013.

PROENÇA, L. C.; GHISI, E. Water End-Uses in Brazilian Office Buildings. Resources,

Conservation and Recycling, v. 54, n. 8, p. 489500, 2010.

R CORE TEAM. R: a language and environment for statistical computing. R Foundation for Statistical Computing, Viena, Áustria. 2016. Disponível em: <https://www.R-project.org/>. Acesso em: 2 jul. 2016.

ROMANO, G.; SALVATI, N.; GUERRINI, A. An Empirical Analysis of the Determinants of Water Demand in Italy. Journal of Cleaner Production, v. 130, p. 74-81, 2016.

SAUTCHUK, C. et al. Conservação e Reúso da água em Edificações. São Paulo: Prol Editora Gráfica, 2005.

TECNOLOGIA E QUALIDADE DE SISTEMAS EM ENGENHARIA LTDA. Programa Setorial da Qualidade de Metais Sanitários: relatório setorial $n^{\circ}$ 75. 2017a. Disponível em:

<http://www.asfamas.org.br/datafiles/uploads/rs08 0-simac-ch.pdf. Acesso em: 05 mar. 2018.

TECNOLOGIA E QUALIDADE DE SISTEMAS EM ENGENHARIA LTDA. Programa Setorial da Qualidade de Aparelhos Economizadores de Água: Relatório Setorial Nº 37. 2017b. Disponível em:

http://www.asfamas.org.br/datafiles/uploads/rs080 -simac-ch.pdf>. Acesso em: 05 mar. 2018.

WALFISH, S. A Review of Statistical Outlier Methods. Pharmaceutical Technology, v. 30, n. 11, p. 1-5, 2006.

WILLIS, R. M. et al. End Use Water Consumption in Households: impact of socio-demographic factors and efficient devices. Journal of Cleaner Production, v. 60, p. 107-115, 2013.

YIFA THE PLASTICS LTD. Product

Introduction. Disponível em:

$<$ http://www.hobbytronics.co.uk/datasheets/sensor s/YF-S201.pdf>. Acesso em: 05 mar. 2018.

\section{Agradecimentos}

As autoras agradecem à Fundação Instituto Tecnológico de Joinville (FITEJ), pelo auxílio na compra dos materiais utilizados nessa pesquisa, e ao grupo PET Engenharia Elétrica da UDESC, por desenvolver o equipamento usado para a coleta de dados. 


\section{Roberta J acoby Cureau}

Laboratório de Eficiência Energética em Edificações | Universidade Federal de Santa Catarina | Florianópolis - SC - Brasil | Caixa Postal 476 | CEP 88040-970 | E-mail: robertacureau@hotmail.com

\section{Andreza Kalbusch}

Programa de Pós Graduação em Engenharia Civil | Universidade do Estado de Santa Catarina | Rua Paulo Malschitzki, 200 | J oinville - SC Brasil | CEP 89219-710 | Tel.: (47) 3481-7807 | E-mail: andreza.kalbusch@udesc.br

\section{Elisa Henning}

Programa de Pós Graduação em Engenharia Civil | Universidade do Estado de Santa Catarina | Tel.: (47) 3481-7664 |

E-mail: elisa.henning@udesc.br

\section{Revista Ambiente Construído}

Associação Nacional de Tecnologia do Ambiente Construído

Av. Osvaldo Aranha, 99 - 3o andar, Centro

Porto Alegre - RS - Brasil

CEP $90035-190$

Telefone: +55 (51) 3308-4084

Fax: +55 (51) 3308-4054

www. seer. ufrgs. br/ ambienteconstruido

E-mail: ambienteconstruido@ufrgs.br

(c) (i)

This is an open-access article distributed under the terms of the Creative Commons Attribution License. 